\title{
Evasion of Antiviral Innate Immunity by Porcine Reproductive and Respiratory Syndrome Virus
}

\author{
Tong-Yun Wang ${ }^{1 t}$, Ming-Xia Sun ${ }^{1+}$, Hong-Liang Zhang ${ }^{1}$, Gang Wang ${ }^{1}$, Guoqing Zhan ${ }^{2,3}$, \\ Zhi-Jun Tian', Xue-Hui Caii ${ }^{1}$, Chenhe Su${ }^{2 *}$ and Yan-Dong Tang ${ }^{1 *}$
}

${ }^{1}$ State Key Laboratory of Veterinary Biotechnology, Harbin Veterinary Research Institute of Chinese Academy of Agricultural Sciences, Harbin, China, ${ }^{2}$ Department of Immunology, School of Basic Medical Sciences, Fujian Medical University, Fuzhou, China, ${ }^{3}$ Department of Infectious Disease, Renmin Hospital, Hubei University of Medicine, Shiyan, China

OPEN ACCESS

Edited by:

Chunfu Zheng,

Fujian Medical University, China

Reviewed by:

Guanqun L. Liu,

Cleveland Clinic Florida, United States Jun Han,

China Agricultural University, China

*Correspondence:

Chenhe Su

chenhesu@outlook.com

Yan-Dong Tang

tangyandong2008@163.com;

tangyandong@caas.cn

${ }^{\dagger}$ These authors have contributed equally to this work

Specialty section:

This article was submitted to

Virology,

a section of the journal

Frontiers in Microbiology

Received: 12 April 2021

Accepted: 28 April 2021

Published: 23 June 2021

Citation:

Wang T-Y, Sun $M-X$, Zhang $H-L$, Wang G, Zhan G, Tian Z-J, Cai X-H,

Su C and Tang Y-D (2021) Evasion of Antiviral Innate Immunity by Porcine

Reproductive and Respiratory

Syndrome Virus.

Front. Microbiol. 12:693799.

doi: 10.3389/fmicb.2021.693799
Innate immunity is the front line for antiviral immune responses and bridges adaptive immunity against viral infections. However, various viruses have evolved many strategies to evade host innate immunity. A typical virus is the porcine reproductive and respiratory syndrome virus (PRRSV), one of the most globally devastating viruses threatening the swine industry worldwide. PRRSV engages several strategies to evade the porcine innate immune responses. This review focus on the underlying mechanisms employed by PRRSV to evade pattern recognition receptors signaling pathways, type I interferon (IFN- $\alpha / \beta)$ receptor (IFNAR)-JAK-STAT signaling pathway, and interferonstimulated genes. Deciphering the antiviral immune evasion mechanisms by PRRSV will enhance our understanding of PRRSV's pathogenesis and help us to develop more effective methods to control and eliminate PRRSV.

Keywords: antiviral innate immunity, PRRSV, PRRs, interferon, JAK-STAT, immune evasion, ISGs

\section{INTRODUCTION}

Since its discovery in the late 1980s, porcine reproductive and respiratory syndrome (PRRS) has become one of the most serious swine diseases in the world. PRRS virus (PRRSV), which causes PRRS, is an enveloped RNA virus belonging to the Arteriviridae family (Meulenberg, 2000). PRRSV is divided into two distinct genotypes: Type 1, or European-like (prototype Lelystad), and Type 2, or North American-like (prototype VR-2332) (Nan et al., 2017). PRRSV Types 1 and 2 were reclassified as two species belonging to the genus Porartevirus, PRRSV-1, and PRRSV-2, respectively, according to the current taxonomy (Adams et al., 2016). PRRSV-1 was first reported in Europe (Wensvoort et al., 1991) and then became epidemic in continental Europe and is currently in China (Chen et al., 2011), the United States (Fang et al., 2007), Canada (Dewey et al., 2000), South Korea (Lee et al., 2010), Thailand (Thanawongnuwech et al., 2004), and other countries. PRRSV-2 was first reported in the United States and then spread in some countries in Asia and Europe (Madsen et al., 1998; An et al., 2007; Shi et al., 2010b). PRRSV-1 is divided into Western Europe subtype I, Russia subtype I, subtype II, and subtype III (Shi et al., 2010a). PRRSV-2 is divided into nine lineages, lineag1 9 (Shi et al., 2010a). PRRSV poses a threat to the global pig industry.

PRRSV encodes RNA replicates (ORF1a and ORF1b), four membrane-associated glycoproteins (GP2, GP3, GP4, and GP5), two unglycosylated membrane proteins (E and M), and a nucleocapsid (N) (Meulenberg, 2000; Music and Gagnon, 2010). ORF1a and ORF1b encode polyproteins that are processed into smaller protein products named non-structural proteins (Nsps), which are involved 
in viral RNA synthesis (Kroese et al., 2008; Li et al., 2014; Tang et al., 2016; Wang T. Y. et al., 2019), inducing replicationassociated membrane rearrangement (Snijder et al., 2001; Posthuma et al., 2008), and modulating host immune responses (Fang and Snijder, 2010; Yoo et al., 2010; Sun et al., 2012; Ke and Yoo, 2017; An et al., 2020). Briefly, Nsp1 is involved in modulating subgenomic mRNA synthesis (Kroese et al., 2008), and Nsp2 and Nsp3 play an important role in replicationassociated membrane rearrangement (Snijder et al., 2001; Posthuma et al., 2008). Nsp4 is the main protease responsible for the processing of viral polyproteins (Fang and Snijder, 2010). Nsp9 is an RNA polymerase, and Nsp10 is a helicase; both are key enzymes for arterivirus RNA synthesis and are reported as two key components for the virulence of highly pathogenic PRRSV (Li et al., 2014). Nsp11 is an endoribonuclease; however, its natural substrate is not identified yet (Fang and Snijder, 2010).

PRRSV infection damages innate and adaptive immune response in porcine. Cells of monocyte-macrophage lineage and monocyte-derived dendritic cells are susceptible to PRRSV infection (Loving et al., 2007). PRRSV dramatically destroys porcine immune organs, such as the thymus and bone marrow, which are very important for adaptive immune response (Butler et al., 2019; Wang G. et al., 2019; Wang et al., 2020). Furthermore, it is well recognized that cytokines regulate and participate in innate and adaptive immune responses (Banyer et al., 2000; Belardelli and Ferrantini, 2002; Kabelitz and Medzhitov, 2007). However, PRRSV infection induces alterations of immunoregulatory cytokines, which cause a prolonged delay in the activation of CTL and neutralizing antibody production. Thus, PRRSV infection always causes severe host immune response disorders, such as prolonged viremia, transiently diminishing T-cell immunity, and delayed protective antibody response (Molitor et al., 1997; Labarque et al., 2000; Lopez and Osorio, 2004; Xiao et al., 2004; Wu et al., 2020).

Innate immunity is the first-line host defense that limits the viral spread and regulates the adaptive immune responses. Viral pathogen-associated molecular patterns (PAMPs) are first recognized by host-pathogen recognition receptors (PRRs) and then triggers the associated signaling pathways, such as the interferon (IFN) regulatory factor (IRF) family members and the nuclear factor kappa-light-chain-enhancer of activated $\mathrm{B}$ cells (NF-кB) (Zheng, 2018; Zhu and Zheng, 2020). These transcription factors cooperate to modulate the expression of type I interferons (IFN-I) and, subsequently, evoke the downstream expression of IFN-stimulated genes (ISGs). However, PRRSV has evolved numerous strategies to evade innate antiviral immunity.

\section{Evasion of PRR Signaling Pathways}

The PAMPs of incoming viruses are first recognized by PRRs and activate an IFN response and proinflammatory cytokine responses during viral infection (Chow et al., 2015; Liu and Gack, 2020). Toll-like receptors (TLRs) and RIG-I-like receptors (RLRs) are two major PRRs in mammals that sense the RNA virus (Chow et al., 2015). Among all TLRs, TLR3 recognizes viral double-stranded RNA; TLR7 and TLR8 recognize viral single-stranded RNA (Alexopoulou et al., 2001; Heil et al., 2004). Porcine TLR3 and TLR7 are the best investigated TLRs in porcine cells. For PRRSV infection, expression of porcine TLR3, and TLR7 are upregulated and harbor the ability to elicit activation of IFN (Sang et al., 2008a,b; Liu et al., 2009; Miller et al., 2009). Activation of TLR3 by dsRNA results in the recruitment of Toll-interleukin 1 receptor domaincontaining adapter inducing interferon- $\beta$ (TRIF) through the adaptor protein myeloid differentiation factor 88 (MyD88) independent pathway (Fitzgerald et al., 2003). However, TLRs are limited in detecting viruses because they are expressed in a limited range of cell types (Chow et al., 2015). In contrast, the RLRs, RIG-I, and melanoma differentiation-associated protein 5 (MDA5) expressed in almost all cell types are cytoplasmic RNA helicases that recognize non-self RNA (Chow et al., 2015, 2018; Rehwinkel and Gack, 2020). Porcine RIG-I, MDA5, and mitochondrial antiviral signaling protein (MAVS, also known as IPS-1/VISA/Cardif) are important sensors/adaptors to produce type I IFN in the porcine innate immune system (Wang et al., 2008; Husser et al., 2011; Dong et al., 2013). RIG-I or MDA5 recognize intracellular dsRNA via $\mathrm{DExD} / \mathrm{H}$-box helicase domains. Caspase recruitment domains (CARDs) of RIG-I or MDA5 interact with the counterpart domains of MAVS (Kawai et al., 2005). Although different adaptors are utilized, both pathways converge to stimulate the two downstream kinases, Tank-binding kinase 1 (TBK1), and inhibitor of $\kappa \mathrm{B}$ kinase $\varepsilon(\mathrm{IKK} \varepsilon)$, resulting in the phosphorylation and activation of transcription factors, such as IFN regulatory factor 3 (IRF3), NF- $\kappa$ B, and AP-1 (Fitzgerald et al., 2003). These transcription factors coordinate in forming a transcriptionally competent enhanceosome that produces type I IFN and proinflammatory cytokine responses (Thanos and Maniatis, 1995). Type I IFNs are produced upon infection of animal cells with viruses, and they are responsible for the first line of defense during virus infection (De Maeyer and De Maeyer-Guignard, 1998; Bogdan, 2000). Type I IFNs have a broad and diverse impact on the priming of expansion and maturation of adaptive immunity (Bogdan, 2000; Theofilopoulos et al., 2005). PRRSV has evolved complex strategies to evade type I IFN restriction as illustrated in Figure 1, which is discussed in detail.

\section{Targeting RIG-I and MAVS}

RIG-I and MDA5 are well-conserved cytoplasmic PRRs that detect viral RNAs and interact with the downstream adaptor MAVS and activate the antiviral signaling pathway ( $\mathrm{Wu}$ and Hur, 2015). Both RIG-I and MAVS are critical for Type I IFN signaling. A previous study shows that PRRSV infection inhibits IFN $\beta$ production primarily by interfering with the MAVS activation in the RIG-I signaling pathway (Luo et al., 2008). Further studies demonstrate that Nsp4 and Nsp11 target RIGI and/or MAVS. PRRSV Nsp4 is a 3C-like protease (3CLSP), cleaves MAVS at Glu268 and, thus, inhibits Type I IFN signaling (Dong et al., 2015). PRRSV Nsp11 decreases MAVS and RIGI mRNA, and an endoribonuclease activity is critical for the antagonism (Sun et al., 2016).

\section{Targeting IFN Regulatory Factor 3 (IRF3)}

IRF3 is a key node in the IFN signaling pathway, and it remains in the cytoplasm of unstimulated cells; however, when 


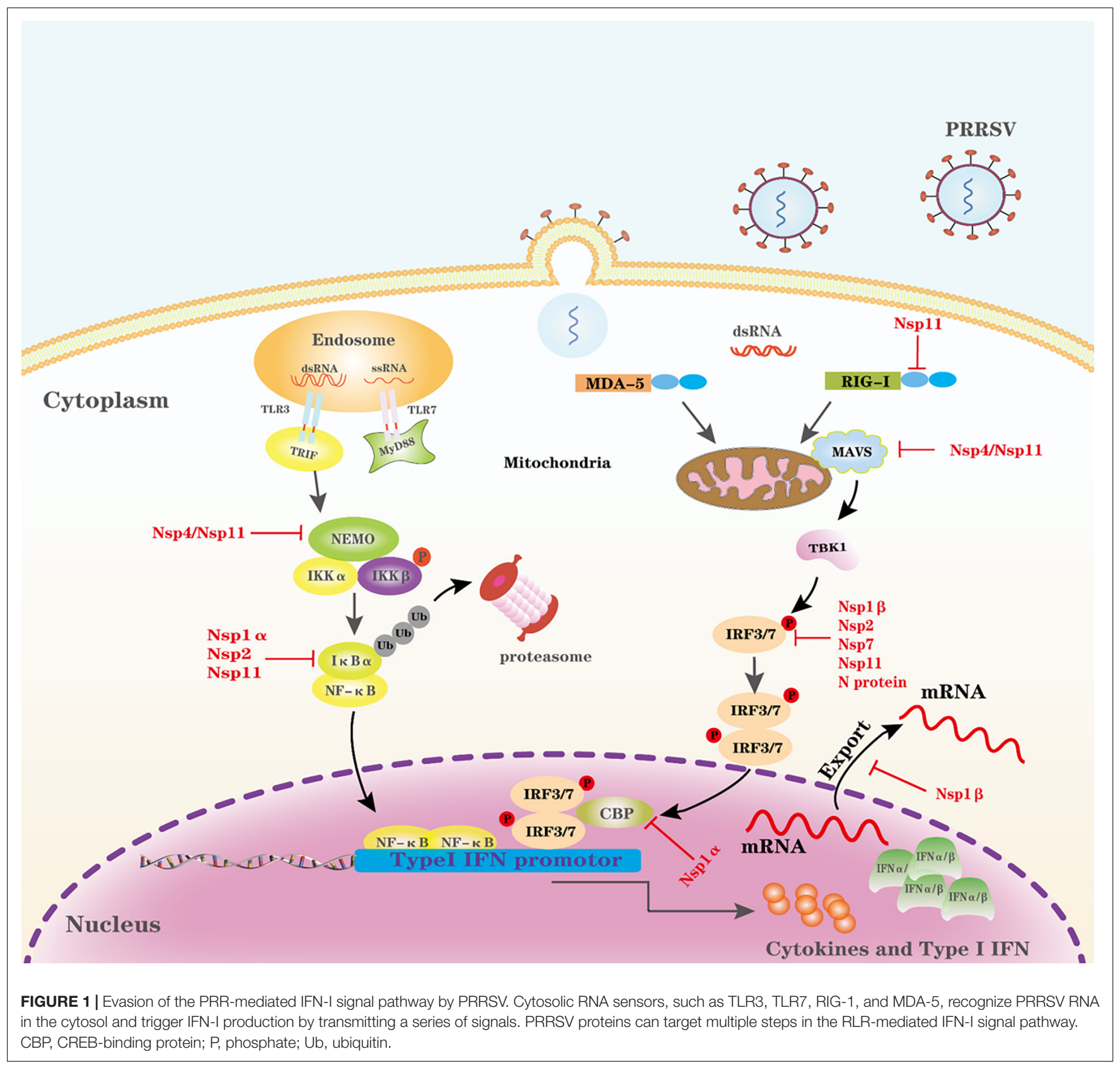

cells are infected by viruses, IRF3 is phosphorylated at various serine and threonine residues at the $\mathrm{C}$ terminus, and then phosphorylated IRF3 homodimerizes and translocates into the nucleus (Yoneyama et al., 2002; Hiscott et al., 2003). In addition, IRF3 C-terminal phosphorylation is required for association with the histone acetyltransferase nuclear proteins CBP [CREB (cyclic AMP responsive element binding)-binding protein] and p300 causing IRF3 to shuttle into the nucleus to induce transcription through distinct positive regulatory domains in the type I IFN promoters (Yoneyama et al., 1998; Hiscott et al., 1999). PRRSV antagonizes IRF3 by following strategies. First, PRRSV Nsp1 $\beta$ significantly blocks dsRNA-induced phosphorylation and nuclear translocation of IRF3 (Beura et al., 2010). Furthermore,
PRRSV Nsp2 also antagonizes activation of IRF3 by inhibiting its phosphorylation and nuclear translocation, and the cysteine protease domain (PL2) of Nsp2 is required to antagonize IRF3 (Li et al., 2010). PRRSV Nsp11 is demonstrated to have an inhibitory effect on IRF3 activation, and this activity is endoribonuclease dependent (Shi et al., 2011). Last, PRRSV $\mathrm{N}$ protein similarly antagonizes IRF3 activation as Nsp1 $\beta$ and Nsp2, and it significantly abrogates dsRNA-induced IRF3 phosphorylation and nuclear translocation (Sagong and Lee, 2011). However, the underlying mechanisms to antagonize IRF3 activation by the above viral proteins are unclear because there is no report on whether these viral proteins interact directly or indirectly with IRF3. 


\section{Targeting IFN Regulatory Factor 7 (IRF7)}

Interferon regulatory factor 7 (IRF7) is a multifunctional transcription factor that was originally discovered during Epstein-Barr virus (EBV) infection, and it has been recognized as one of the major players in virally induced IFN signaling (Zhang and Pagano, 2002). Posttranslational modifications of IRF7 have important roles in regulating IRF7 activity, including phosphorylation and ubiquitination (Zhang and Pagano, 2002). PRRSV could downregulate the expression of IRF7 in pulmonary alveolar macrophages, and this activity is attributed to Nsp7 (Liu et al., 2019). However, the mechanism that PRRSV Nsp7 inhibits the expression of IRF7 is unclear, and this needs further investigation.

\section{CREB (Cyclic AMP Responsive Element Binding)-Binding Protein (CBP)}

The CBP coactivator is a histone acetyltransferase; p300 and $\mathrm{CBP}$ are partners that cooperatively play a key role in transcriptional responses to disparate extracellular and intracellular signals (Giordano and Avantaggiati, 1999). CBP and p300 play multifunctional roles of the coactivator in transcriptional regulation, and in fact, many transcription factors have been reported to bind CBP (Goldman et al., 1997). PRRSV Nsp1 $\alpha$ could degrade CBP in a proteasome-dependent manner, and its degradation prevents $\mathrm{CBP}$ recruitment for enhanceosome assembly, resulting in a blockage of IFN response (Kim et al., 2010). The Nsp1 $\alpha$ contains three distinct functional motifs; a papain-like cysteine protease alpha ( $\mathrm{PCP} \alpha)$ motif, an N-terminal zinc finger motif (ZF1), and a recently discovered C-terminal zinc finger motif (ZF2). ZF1 is a required component of Nsp1 $\alpha$ to suppress IFN production. Wild-type Nsp1 $\alpha$ localizes in both the nucleus and the cytoplasm, but the ZF1 mutants lose their IFN suppression by inhibiting Nsp1 $\alpha$ shuttling from the cytoplasm to the nucleus (Han et al., 2013; Han and Yoo, 2014). CBP degradation is most likely the primary mechanism for IFN suppression mediated by PRRSV (Han et al., 2013; Han and Yoo, 2014).

\section{NF- $\mathrm{B}$}

\section{Targeting NF-кB Essential Modulator (NEMO/IKK $\gamma$ )}

Nuclear factor- $\mathrm{KB}(\mathrm{NF}-\kappa \mathrm{B})$ essential modulator (NEMO), a component of the inhibitor of $\kappa \mathrm{B}$ kinase (IKK) complex (which includes two kinases, IKK $\alpha$ and IKK $\beta$ ), regulates NF- $\mathrm{KB}$ signaling by binding to ubiquitin chains (Kensche et al., 2012). IKK complex is a critical regulator for its downstream signaling by phosphorylating Iк $\mathrm{B} \alpha$, leading to its subsequent degradation by the ubiquitin-proteasome system (Hayden and Ghosh, 2008). To activate the IKK complex, NEMO binding to ubiquitin chains is a critical step in linking upstream ubiquitin signals (Kensche et al., 2012). PRRSV nsp4 is an antagonist of NEMO, which cleave NEMO at multiple sites (Huang et al., 2014; Chen et al., 2019). Further study demonstrates that aspartic acid at residue 185 modulates Nsp4 catalytic activity, and this activity is responsible for NEMO cleavage (Wei et al., 2020). Linear ubiquitination targeting NEMO plays a critical role in the regulation of NF- $\mathrm{KB}$ signaling. PRRSV Nsp11 cooperates with swine linear ubiquitination-specific deubiquitinase, ovarian tumor domain deubiquitinase with linear linkage specificity (OTULIN) to remove linear ubiquitination of NEMO, which subsequently blocks the activation of NF-KB signaling (Su et al., 2018).

\section{Targeting I-Kappa-B-Alpha $(\mathrm{I} \kappa \mathrm{B} \alpha)$}

$\mathrm{NF}-\kappa \mathrm{B}$ plays a critical role in coordinating the expression of numerous genes that regulate immune responses (Li and Verma, 2002). NF- $\mathrm{\kappa B}$ proteins are present in the cytoplasm in association

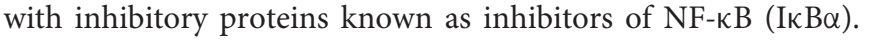
After activation by upstream signals, the ІкB proteins become phosphorylated, ubiquitylated, and subsequently degraded by the K48-linked ubiquitin-proteasome pathway (Li and Verma,

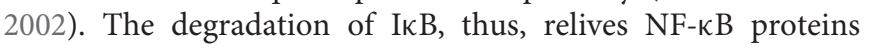
to translocate to the nucleus and regulate the transcription of many genes, including the production of IFN-I and inflammatory chemokines.

I $\mathrm{B} \alpha$ is an inhibitor of NF- $\kappa \mathrm{B}$, blocking nuclear translocation and DNA binding. For NF- $\kappa B$ activation, I $\mathrm{IB} \alpha$ is phosphorylated by upstream kinases and then is ubiquitinated, leading to proteosome-mediated degradation. NF- $\mathrm{\kappa B}$ is then released into the nucleus, where it activates a slew of genes involved in immune and inflammatory responses (Jacobs and Harrison, 1998; Seth et al., 2005). Nsp1 $\alpha$ has been reported to counteract I $\mathrm{B} \alpha$ by inhibiting its phosphorylation, which is a key step for NF- $\mathrm{BB}$ activation, and a further study indicates that Met180 and C-terminal 14 amino acids of the Nsp1 $\alpha$ are crucial for inhibitory activities (Song et al., 2010). PRRSV nsp2 has a cysteine protease domain at its $\mathrm{N}$ terminus that belongs to the ovarian tumor (OTU) protease family. The PRRSV Nsp2 OTU domain has ubiquitin-deconjugating activity, and this domain potently inhibits NF- $\kappa \mathrm{B}$ activation by interfering with the polyubiquitination process of $\mathrm{I} \mathrm{B} \alpha$, preventing Ік $\mathrm{B} \alpha$ degradation (Sun et al., 2010). Except for Nsp2, PRRSV Nsp11 encodes a unique and conserved endoribonuclease (nidovirus-specific endoribonuclease, NendoU) with DUB activity that specifically removes Lysine 48 (K48)-linked polyubiquitin chains of IкB $\alpha$ (Wang et al., 2015). Overall, PRRSV engages Nsp1 $\alpha$, Nsp2, and Nsp11 to interfere with the polyubiquitination process of $\mathrm{I} \kappa \mathrm{B} \alpha$.

\section{Evasion of IFNAR-JAK-STAT Pathway}

A typical PRRSV infection in pigs is characterized by delayed production and low titer of virus-neutralizing antibodies as well as weak cell-mediated immune response. One possible explanation for PRRSV-induced weak protective immune responses is that PRRSV may disrupt cytokine-mediated JAKSTAT signaling (Yang and Zhang, 2017). Various cytokines activate a JAK-STAT signaling pathway; nearly 40 cytokine receptors signal through combinations of four JAK (JAK1, JAK2, JAK 3, and Tyk2) and seven STAT (STAT1-STAT7) family members, which are involved in the regulation of cell growth, proliferation, differentiation, apoptosis, angiogenesis, immunity, and inflammatory response (Rawlings et al., 2004; Murray, 2007). Cytokines first bind their receptors, which cytoplasmic domains are associated with JAK tyrosine kinases, and then two JAKs are brought into proximity allowing trans-phosphorylation, 
which further induces the multimerization (homodimers or heteromultimers depend on the type of cytokine) of receptor subunits. The activated JAKs subsequently phosphorylate the major substrates, STATs, which are latent transcription factors. STATs contain a conserved tyrosine residue near the C-terminus that is responsible for phosphorylation by JAKs. STATs form dimers by interacting with a conserved $\mathrm{SH} 2$ domain. Phosphorylated STATs dimers enter the nucleus mediated by importin $\alpha-5$ (also known as karyopherin- $\alpha 1$, KPNA1) and the Ran nuclear import pathway allows phosphorylated STATs dimers to enter the nucleus and bind specific regulatory sequences to modulate target gene expression (Imada and Leonard, 2000; Rawlings et al., 2004). Negative regulators of the JAK/STAT pathway fall into three categories: suppressors of cytokine signaling (SOCS), protein inhibitors of activated stats (PIAS), and protein tyrosine phosphatases (PTPs) (Starr and Hilton, 1999; Greenhalgh and Hilton, 2001).

PRRSV uses multiple strategies to antagonize the JAK-STAT signaling pathway (Yang and Zhang, 2017). PRRSV infection is shown to disrupt the activation and signaling pathway of type I IFNs by inhibiting ISGF3 nuclear translocation (Patel et al., 2010). PRRSV Nsp1 $\beta$ induces karyopherin- $\alpha 1$ (KPNA1) degradation, which is a critical factor responsible for ISGF3 nuclear translocation; therefore, Nsp1 prevents IFN-induced ISGF3 complex nuclear translocation (Chen et al., 2010; Patel et al., 2010). Further study illustrates that Nsp1 $\beta$ Valine-19 is essential for inducing degradation of KPNA1 (Wang et al., 2013b). N protein expression leads to inhibition of IFN-induced elevation of STAT2 levels and ISGF3 nuclear translocation. However, the detailed mechanism was not well established (Wang et al., 2013a). PRRSV infection-induced STAT2 degradation through the ubiquitin-proteasome degradation pathway and Nsp11 is shown to interact with STAT2 directly and be responsible for STAT2 degradation (Yang et al., 2019). Interestingly, Nsp11 mediated STAT2 degradation is not dependent on the endoribonuclease activity, and amino acid residue $\mathrm{K} 59$ in nsp11 is required for STAT2 degradation (Yang et al., 2019). A recent study also demonstrates that Nsp11 interacts with interferon regulatory factor 9 (IRF9), which impairs the formation and nuclear translocation of ISGF3, and this activity is also independent of endoribonuclease activity (Wang D. et al., 2019).

Interestingly, PRRSV also modulates the JAK/STAT pathway by other strategies, such as microRNA and SOCS. PRRSV infection upregulates a host microRNA, miR-30 c, to target JAK1 and, subsequently, promotes PRRSV replication (Zhang et al., 2016). PRRSV also upregulates SOCS1, a negative regulator for the JAK/STAT pathway (Wysocki et al., 2012). The PRRSV N protein can increase SOCS1 activity, and nuclear localization signal-2 (NLS-2) is required for SOCS1 induction (Luo et al., 2020a). The evasion of the IFNAR-JAK-STAT signaling pathway by PRRSV is illustrated in Figure 2. With the continuous exploration in this field, we think more and more strategies by which PRRSV evades the JAK-STAT pathway will be uncovered.

\section{Evasion of ISGs and Intrinsic Antiviral Proteins}

Many intrinsic antiviral proteins can inhibit PRRSV replication, but we only discuss several proteins antagonized by PRRSV. The evasion of ISGs and intrinsic antiviral proteins by PRRSV is illustrated in Figure 3.

\section{Proprotein Convertase Subtilisin/Kexin Type 9 (PCSK9)}

Proprotein convertase subtilisin/Kexin type 9 (PCSK9) is an enzyme that belongs to the subtilisin-like serine proteases family that participates in the proteolytic maturation of various proteins, such as hormones and cytokines (Seidah and Chretien, 1999). PCSK9 is a key component for plasma cholesterol metabolism, which controls low-density lipoprotein receptor (LDLR) levels by increasing LDLR degradation (Cohen et al., 2005; Maxwell et al., 2005). It is reported that PCSK9 can impede the replication of several viruses through different mechanisms. Dengue virus (DENV) infection induces the expression of PCSK9, which inhibits the recycling of LDL receptors and reduces uptake of LDL cholesterol in cells, compensatively; this cholesteroldeprived cell then activates and increases cholesterol synthesis in the endoplasmic reticulum, which subsequently decreases the expression of antiviral type I interferon genes (Gan et al., 2020). Hepatitis $\mathrm{C}$ virus (HCV) infection modulates the HCV receptors LDLR and CD81 on the liver cell surface, and PCSK9 modulates CD81 cell surface expression in an LDLR-independent manner (Labonte et al., 2009). For PRRSV, PCSK9 is induced by PRRSV infection in porcine alveolar macrophages at an early stage, and PCSK9 protein suppresses the replication of PRRSV by targeting the virus receptor CD163, which is important for PRRSV infection (Wang et al., 2018; Zhang et al., 2020). Nsp11 could antagonize PCSK9's antiviral activity, and this activity is endoribonuclease activity-dependent (Zhang et al., 2020).

\section{The Tripartite Motif-Containing 25 (TRIM25)}

TRIM25 is an E3 ubiquitin ligase that is thought to be a crucial component in the activation of RIG-1 signaling. Recently, TRIM25 was identified as an RNA binding protein that may be essential for its function in innate immunity (Choudhury et al., 2020). The K63-linked ubiquitination of RIG-I by TRIM25 is needed to initiate the intracellular antiviral responses (Gack et al., 2007; Martin-Vicente et al., 2017). Influenza A virus NS1 interacts with TRIM25, thus blocking TRIM25 multimerization and RIG-I CARD domain ubiquitination (Gack et al., 2009). The severe acute respiratory syndrome coronavirus (SARS), and Middle East respiratory syndrome CoV (MERS-CoV) N protein inhibit TRIM25-mediated RIGI ubiquitination, resulting in the inhibition of IFN production (Hu et al., 2017). PRRSV also uses $\mathrm{N}$ protein to interfere with TRIM25-RIG-I interaction by competitively interacting with TRIM25. $\mathrm{N}$ protein suppresses IFN- $\beta$ production by inhibiting TRIM25 expression and TRIM25-mediated RIG-I ubiquitination (Zhao et al., 2019a). It seems like there is a common mechanism for nidoviruses to antagonize TRIM25. It is reported that a specific DENV lineage encodes sgRNA antagonizing TRIM25. DENV-2 produces subgenomic RNA during replication, which shows sequence-dependent binding to and prevention of TRIM25 deubiquitylation, which is a specific viral RNA-host protein interaction to suppress the innate immune responses (Manokaran et al., 2015); however, whether 


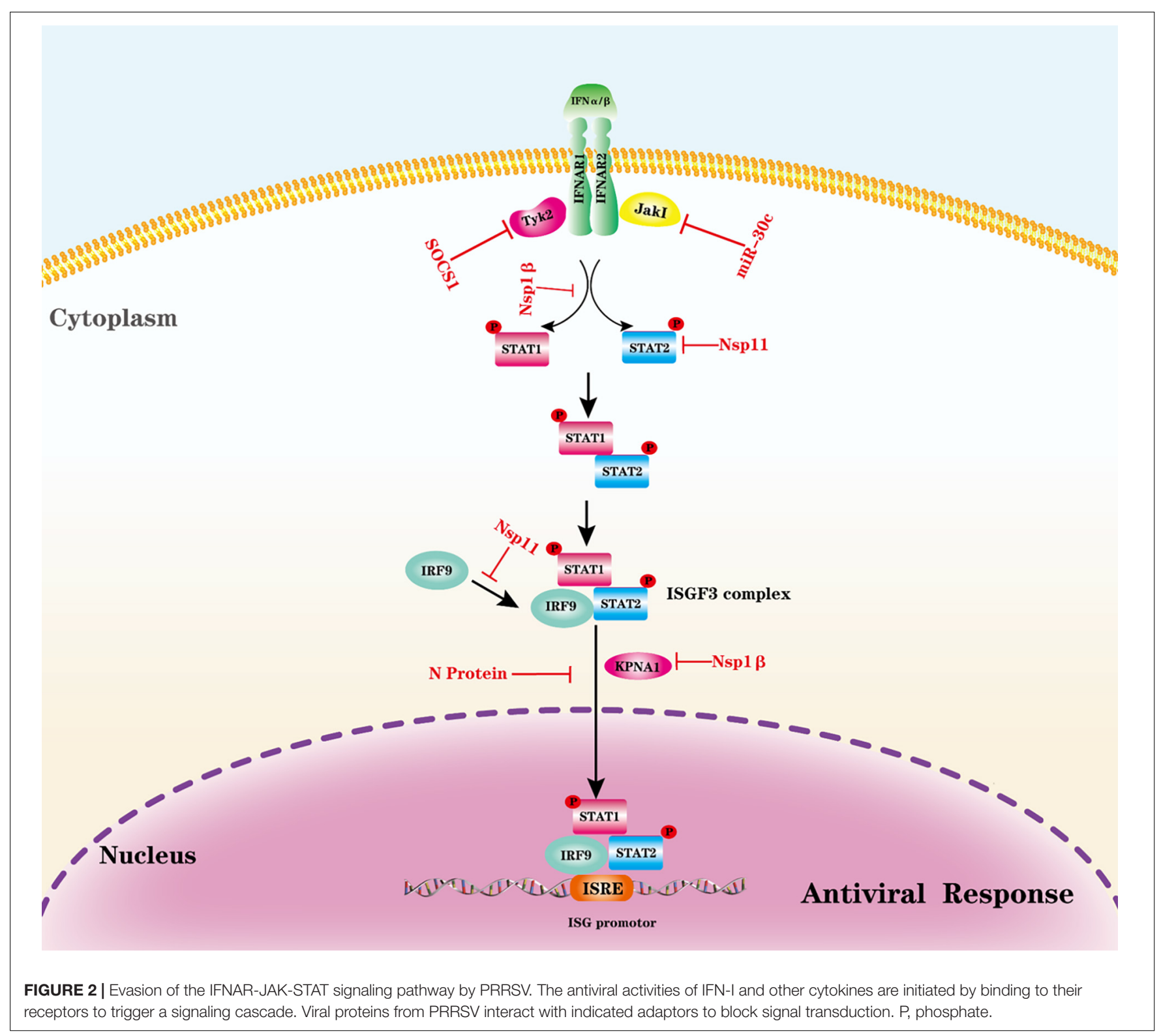

PRRSV has a similar mechanism to antagonize TRIM25 needs further exploration.

\section{Zinc Finger Antiviral Protein, ZAP}

Zinc-finger antiviral protein (ZAP), also known as zinc finger $\mathrm{CCCH}$-type containing antiviral 1 (ZC3HAV1), is another ISG that was originally discovered as an antiretroviral factor (inhibition of retroviral RNA production by ZAP, a CCCH-type zinc finger protein) (Gao et al., 2002). ZAP in antiviral immunity is mainly based on its RNA binding property; in most known cases, ZAP recognizes viral RNA and recruits both the $5^{\prime}$ and $3^{\prime}$ mRNA RNA decay machinery to degrade the target RNAs, which is considered to be the principal antiviral mechanism mediated by ZAP (Zhu et al., 2011; Luo et al., 2020b; Wang and Zheng, 2020). Viral RNAs harbor the ZAP-responsive element (ZRE), a characteristic ZAP binding site; however, the corresponding
ZRE position in each virus RNA sequence varies (Wang and Zheng, 2020). In PRRSV infection, ZAP is upregulated and then suppresses PRRSV replication at the early stage of replication; Nsp9 is reported to interact with ZAP (Zhao et al., 2019b). However, the mechanism that ZAP inhibits PRRSV replication is not well illustrated. Whether PRRSV harbors the ZRE or viral RNA degrades by ZAP is unclear. Interestingly, PRRSV could escape ZAP restriction by Nsp4, which cleaves ZAP dependent on its protease activity (Zhao et al., 2020). Further study reveals that serine 180 of Nsp4 is necessary for efficient degradation of ZAP, and the mutation at residue 180 is crucial for degradation of ZAP (Zhao et al., 2020).

\section{IFITM1 and Tetherin}

Interferon-inducible transmembrane proteins (IFITMs) are critical antiviral factors that belong to a family of small 


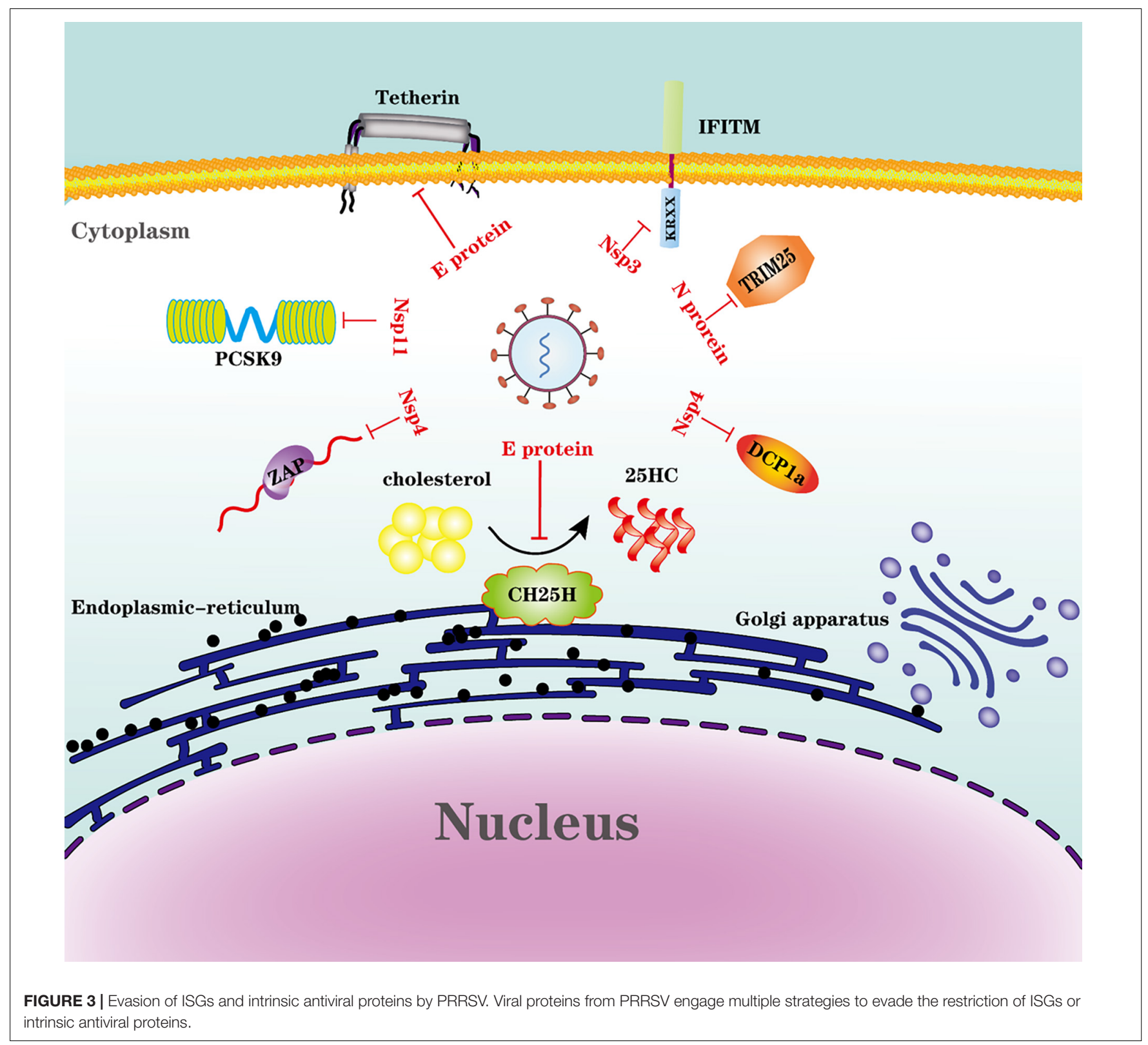

transmembrane proteins. IFITM proteins can impair broadspectrum viral infection through multiple mechanisms, including limiting the viral entry, decreasing viral gene expression and viral protein synthesis, restricting viral assembly, and reducing viral infectivity (Liao et al., 2019). IFITM1 is one of the IFITMs. The potency and breadth of viruses restricted by IFITM1 are determined by its C-terminal non-canonical dibasic sorting signal KRXX, which suppresses certain viruses by regulating their intracellular dissemination ( $\mathrm{Li}$ et al., 2015). PRRSV Nsp3 could counteract the restriction of IFITM1 by interaction with IFITM1 and then inducing the proteasome-dependent degradation of IFITM1 (Wang et al., 2014).

Tetherin is a type II single-pass transmembrane protein known as BST-2, CD317, or HM1.24. It has a cytoplasmic N-terminal region, followed by a transmembrane domain, a coiled-coil extracellular domain, and a glycosylphosphatidylinositol (GPI) anchor at the C-terminus (Kupzig et al., 2003). Tetherin inhibits viral replication by preventing newly formed virions from the host cell surface (Malim and Emerman, 2008; Neil and Bieniasz, 2009). PRRSV E protein could antagonize tetherin by interaction with tetherin and further partially remove tetherin away from the cell surface (Wang et al., 2014).

\section{mRNA-Decapping Enzyme 1a (DCP1a)}

The mRNA-decapping enzyme 1a (DCP1a) is a cofactor involved in the removal of the 5'-methylguanosine cap from eukaryotic mRNA in the granules known as processing bodies (P-bodies) (Sheth and Parker, 2003; Franks and Lykke-Andersen, 2008). DCP1a is involved in P-body formation, maintenance, and 
regulation (Franks and Lykke-Andersen, 2008). DCP1a also induces translational arrest by activating double-stranded RNAdependent protein kinase (PKR) (Dougherty et al., 2014). Furthermore, DCP1a has recently been identified as an ISG (Schoggins et al., 2011, 2014). DCP1a can restrict poliovirus infection by inducing translational arrest (Dougherty et al., 2014). DCP1a has been demonstrated to inhibit PRRSV, whereas the mechanism is unclear (Tao et al., 2018). By counteracting DCP1a inhibition, PRRSV uses Nsp4 to cleave DCP1a, and the cleaved site is at glutamic acid 238 (E238) of porcine DCP1a; interestingly, this cleavage site is species-specific (Tao et al., 2018).

\section{Cholesterol 25-Hydroxylase (CH25H)}

Cholesterol-25-hydroxylase $(\mathrm{CH} 25 \mathrm{H})$ is one of the ISGs identified as a broadly antiviral ISG (Liu et al., 2013). CH25H is an endoplasmic-reticulum-associated enzyme catalyzing cholesterol oxidation to a soluble antiviral factor, 25-hydroxycholesterol (25HC) (Holmes et al., 2011). 25HC broadly inhibits enveloped viruses by blocking virus entry (Liu et al., 2013). For some viruses, including PRRSV, $\mathrm{CH} 25 \mathrm{H}$ could inhibit viral replication through enzyme activity-dependent and independent mechanisms (Lv et al., 2019; Li et al., 2020). CH25H restricts PRRSV replication by inhibiting virus entry and degrading Nsp1 $\alpha$ via the ubiquitin-proteasome pathway with K169 in the Nsp1 protein serving as the main ubiquitination location (Ke et al., 2017). PRRSV has also evolved several strategies to overcome the restriction of $\mathrm{CH} 25 \mathrm{H}$. First, PRRSV E protein interacts with $\mathrm{CH} 25 \mathrm{H}$ and then degrades it via the ubiquitin-proteasome pathway, and the ubiquitination site is identified at Lys28 (Ke et al., 2019). Second, Nsp1 $\beta$ and Nsp11 mediate the degradation of $\mathrm{CH} 25 \mathrm{H}$ via a lysosomal pathway with His159 in Nsp1 $\beta$ and NendoU involvement in Nsp11 playing critical roles in $\mathrm{CH} 25 \mathrm{H}$ downregulation (Dong et al., 2018). However, $\mathrm{CH} 25 \mathrm{H}$ has no interaction with Nsp $1 \beta$ or Nsp11, and the detail mechanisms by which Nsp1 $\beta$ and Nsp11 mediates $\mathrm{CH} 25 \mathrm{H}$ degradation need further exploration (Dong et al., 2018).

\section{FUTURE PERSPECTIVE}

Viruses have evolved multiple strategies to evade innate immune surveillance. This review summarizes how PRRSV engages several strategies to evade the porcine RNA sensing pathway of innate immune responses. However, the roles of DNA sensing pathways in PRRSV infection are unclear. Although there is no specific antagonism reported so far, the role of DNA sensors, such as IFI16, are reported to have an anti-PRRSV activity (Chang et al., 2019). There is emerging evidence showing the contribution of damaged host DNA, such as mitochondrial DNA, to innate

\section{REFERENCES}

Adams, M. J., Lefkowitz, E. J., King, A. M., Harrach, B., Harrison, R. L., Knowles, N. J., et al. (2016). Ratification vote on taxonomic proposals to the international committee on taxonomy of viruses (2016). Arch. Virol. 161, 2921-2949. doi: 10.1007/s00705-016-2977-6 immune responses against RNA viruses. Furthermore, PRRSV is highly genetically variable. How the genetic variations affect the immune modulation function of the viral proteins is the key to understanding the difference in virulence of different PRRSV strains, which needs further exploration in the future.

PRRSV has a potent spatiotemporal regulation ability to immune response. First, it evades TLR and RLR signaling to suppress the production of Type I IFNs, which are key components that modulate the development and maturation of adaptive immunity. Second, it also impairs antiviral response by targeting the IFNAR-JAK-STAT pathway. Last, PRRSV also evades ISGs and intrinsic antiviral proteins to promote viral replication. We think there are other undiscovered strategies for PRRSV to evade the innate immune response, and further investigation is needed.

In addition to the innate immune signal pathways mentioned above, unfolded protein responses, stress granules, and apoptosis are key components of cellular innate immunity. However, it seems that only UPR could be effectively counteracted by PRRSV (Gao et al., 2019). For stress granules and apoptosis, PRRSV infection induces but does not inhibit these responses (Catanzaro and Meng, 2019; Ruedas-Torres et al., 2020). Therefore, further studies focused on these directions will help us to comprehensively understand how PRRSV evades innate immune responses. Deciphering PRRSV evasion of innate immune responses will enhance our understanding of PRRSV's pathogenesis and develop more effective methods to control and eliminate PRRSV, especially for candidate vaccine development that will potently induce both innate and adaptive immune response.

\section{AUTHOR CONTRIBUTIONS}

Y-DT and CS conceptualized the idea and generated the figures. All authors wrote the manuscript, contributed to the article, and approved the submitted version.

\section{FUNDING}

This study was supported by the Heilongjiang Excellent Youth Fund Project (YQ2019C032 and YQ2019C028) and grants from the National Natural Science Foundation of China (32072870).

\section{ACKNOWLEDGMENTS}

We apologize to all colleagues whose contributions were not discussed and cited owing to space constraints. 
An, T. Q., Zhou, Y. J., Liu, G. Q., Tian, Z. J., Li, J., Qiu, H. J., and Tong, G. Z. (2007). Genetic diversity and phylogenetic analysis of glycoprotein 5 of PRRSV isolates in mainland China from 1996 to 2006: coexistence of two NA-subgenotypes with great diversity. Vet. Microbiol. 123, 43-52. doi: 10.1016/j.vetmic.2007.02. 025

Banyer, J. L., Hamilton, N. H., Ramshaw, I. A., and Ramsay, A. J. (2000). Cytokines in innate and adaptive immunity. Rev. Immunogenet. 2, 359-373.

Belardelli, F., and Ferrantini, M. (2002). Cytokines as a link between innate and adaptive antitumor immunity. Trends Immunol. 23, 201-208. doi: 10.1016/ s1471-4906(02)02195-6

Beura, L. K., Sarkar, S. N., Kwon, B., Subramaniam, S., Jones, C., Pattnaik, A. K., et al. (2010). Porcine reproductive and respiratory syndrome virus nonstructural protein lbeta modulates host innate immune response by antagonizing IRF3 activation. J. Virol. 84, 1574-1584. doi: 10.1128/jvi.01326-09

Bogdan, C. (2000). The function of type I interferons in antimicrobial immunity. Curr. Opin. Immunol. 12, 419-424. doi: 10.1016/s0952-7915(00)00111-4

Butler, J. E., Sinkora, M., Wang, G., Stepanova, K., Li, Y., and Cai, X. (2019). Perturbation of thymocyte development underlies the PRRS pandemic: a testable hypothesis. Front. Immunol. 10:1077.

Catanzaro, N., and Meng, X. J. (2019). Porcine reproductive and respiratory syndrome virus (PRRSV)-induced stress granules are associated with viral replication complexes and suppression of host translation. Virus Res. 265, 47-56. doi: 10.1016/j.virusres.2019.02.016

Chang, X., Shi, X., Zhang, X., Wang, L., Li, X., Wang, A., et al. (2019). IFI16 inhibits porcine reproductive and respiratory syndrome virus 2 replication in a MAVS-dependent manner in MARC-145 cells. Viruses 11:1160. doi: 10.3390/ v11121160

Chen, N., Cao, Z., Yu, X., Deng, X., Zhao, T., Wang, L., et al. (2011). Emergence of novel European genotype porcine reproductive and respiratory syndrome virus in mainland China. J. Gen. Virol. 92, 880-892. doi: 10.1099/vir.0.027995-0

Chen, J., Wang, D., Sun, Z., Gao, L., Zhu, X., Guo, J., et al. (2019). Arterivirus nsp4 antagonizes interferon beta production by proteolytically cleaving NEMO at multiple sites. J. Virol. 93, e00385-19.

Chen, Z., Lawson, S., Sun, Z., Zhou, X., Guan, X., Christopher-Hennings, J., et al. (2010). Identification of two auto-cleavage products of nonstructural protein 1 (nsp1) in porcine reproductive and respiratory syndrome virus infected cells: nsp1 function as interferon antagonist. Virology 398, 87-97. doi: 10.1016/j.virol. 2009.11.033

Choudhury, N. R., Heikel, G., and Michlewski, G. (2020). TRIM25 and its emerging RNA-binding roles in antiviral defense. Wiley Interdiscip. Rev. RNA 11:e1588.

Chow, J., Franz, K. M., and Kagan, J. C. (2015). PRRs are watching you: localization of innate sensing and signaling regulators. Virology 47, 104-109. doi: 10.1016/ j.virol.2015.02.051

Chow, K. T., Gale, M. Jr., and Loo, Y. M. (2018). RIG-I and Other RNA sensors in antiviral immunity. Annu. Rev. Immunol. 36, 667-694. doi: 10.1146/annurevimmunol-042617-053309

Cohen, J., Pertsemlidis, A., Kotowski, I. K., Graham, R., Garcia, C. K., and Hobbs, H. H. (2005). Low LDL cholesterol in individuals of African descent resulting from frequent nonsense mutations in PCSK9. Nat. Genet. 37, 161-165. doi: $10.1038 / \mathrm{ng} 1509$

De Maeyer, E., and De Maeyer-Guignard, J. (1998). Type I interferons. Int. Rev. Immunol. 17, 53-73.

Dewey, C., Charbonneau, G., Carman, S., Hamel, A., Nayar, G., Friendship, R., et al. (2000). Lelystad-like strain of porcine reproductive and respiratory syndrome virus (PRRSV) identified in Canadian swine. Can. Vet. J. 41, 493-494.

Dong, H., Zhou, L., Ge, X., Guo, X., Han, J., and Yang, H. (2018). Porcine reproductive and respiratory syndrome virus nsplbeta and nsp11 antagonize the antiviral activity of cholesterol-25-hydroxylase via lysosomal degradation. Vet. Microbiol. 223, 134-143. doi: 10.1016/j.vetmic.2018.08.012

Dong, J., Xu, S., Wang, J., Luo, R., Wang, D., Xiao, S., et al. (2015). Porcine reproductive and respiratory syndrome virus $3 \mathrm{C}$ protease cleaves the mitochondrial antiviral signalling complex to antagonize IFN-beta expression. J. Gen. Virol. 96, 3049-3058. doi: 10.1099/jgv.0.000257

Dong, X. Y., Liu, W. J., Zhao, M. Q., Wang, J. Y., Pei, J. J., Luo, Y. W., et al. (2013). Classical swine fever virus triggers RIG-I and MDA5-dependent signaling pathway to IRF-3 and NF-kappaB activation to promote secretion of interferon and inflammatory cytokines in porcine alveolar macrophages. Virol. J. 10:286. doi: $10.1186 / 1743-422 x-10-286$
Dougherty, J. D., Reineke, L. C., and Lloyd, R. E. (2014). mRNA decapping enzyme 1a (Dcpla)-induced translational arrest through protein kinase R (PKR) activation requires the $\mathrm{N}$-terminal enabled vasodilator-stimulated protein homology 1 (EVH1) domain. J. Biol. Chem. 289, 3936-3949. doi: 10.1074/jbc. m113.518191

Fang, Y., Schneider, P., Zhang, W. P., Faaberg, K. S., Nelson, E. A., and Rowland, R. R. (2007). Diversity and evolution of a newly emerged North American Type 1 porcine arterivirus: analysis of isolates collected between 1999 and 2004. Arch. Virol. 152, 1009-1017. doi: 10.1007/s00705-007-0936-y

Fang, Y., and Snijder, E. J. (2010). The PRRSV replicase: exploring the multifunctionality of an intriguing set of nonstructural proteins. Virus Res. 154, 61-76. doi: 10.1016/j.virusres.2010.07.030

Fitzgerald, K. A., Mcwhirter, S. M., Faia, K. L., Rowe, D. C., Latz, E., Golenbock, D. T., et al. (2003). IKKepsilon and TBK1 are essential components of the IRF3 signaling pathway. Nat. Immunol. 4, 491-496. doi: 10.1038/ni921

Franks, T. M., and Lykke-Andersen, J. (2008). The control of mRNA decapping and P-body formation. Mol. Cell 32, 605-615. doi: 10.1016/j.molcel.2008.11.001

Gack, M. U., Albrecht, R. A., Urano, T., Inn, K. S., Huang, I. C., Carnero, E., et al. (2009). Influenza A virus NS1 targets the ubiquitin ligase TRIM25 to evade recognition by the host viral RNA sensor RIG-I. Cell Host Microbe. 5, 439-449. doi: 10.1016/j.chom.2009.04.006

Gack, M. U., Shin, Y. C., Joo, C. H., Urano, T., Liang, C., Sun, L., et al. (2007). TRIM25 RING-finger E3 ubiquitin ligase is essential for RIG-I-mediated antiviral activity. Nature 446, 916-920. doi: 10.1038/nature05732

Gan, E. S., Tan, H. C., Le, D. H. T., Huynh, T. T., Wills, B., Seidah, N. G., et al. (2020). Dengue virus induces PCSK9 expression to alter antiviral responses and disease outcomes. J. Clin. Invest. 130, 5223-5234. doi: 10.1172/jci137536

Gao, G., Guo, X., and Goff, S. P. (2002). Inhibition of retroviral RNA production by ZAP, a CCCH-type zinc finger protein. Science 297, 1703-1706. doi: 10.1126/ science. 1074276

Gao, P., Chai, Y., Song, J., Liu, T., Chen, P., Zhou, L., et al. (2019). Reprogramming the unfolded protein response for replication by porcine reproductive and respiratory syndrome virus. PLoS Pathog. 15:e1008169. doi: 10.1371/journal. ppat.1008169

Giordano, A., and Avantaggiati, M. L. (1999). p300 and CBP: partners for life and death. J. Cell Physiol. 181, 218-230. doi: 10.1002/(sici)1097-4652(199911)181: $2<218:$ :aid-jcp4>3.0.co;2-5

Goldman, P. S., Tran, V. K., and Goodman, R. H. (1997). The multifunctional role of the co-activator CBP in transcriptional regulation. Recent Prog. Horm. Res. 52, 103-119; discussion119-120.

Greenhalgh, C. J., and Hilton, D. J. (2001). Negative regulation of cytokine signaling. J. Leukoc. Biol. 70, 348-356.

Han, M., Du, Y., Song, C., and Yoo, D. (2013). Degradation of CREB-binding protein and modulation of type I interferon induction by the zinc finger motif of the porcine reproductive and respiratory syndrome virus nsplalpha subunit. Virus Res. 172, 54-65. doi: 10.1016/j.virusres.2012.12.012

Han, M., and Yoo, D. (2014). Modulation of innate immune signaling by nonstructural protein 1 (nsp1) in the family Arteriviridae. Virus Res .194, 100-109. doi: 10.1016/j.virusres.2014.09.007

Hayden, M. S., and Ghosh, S. (2008). Shared principles in NF-kappaB signaling. Cell 132, 344-362. doi: 10.1016/j.cell.2008.01.020

Heil, F., Hemmi, H., Hochrein, H., Ampenberger, F., Kirschning, C., Akira, S., et al. (2004). Species-specific recognition of single-stranded RNA via toll-like receptor 7 and 8. Science 303, 1526-1529. doi: 10.1126/science.1093620

Hiscott, J., Grandvaux, N., Sharma, S., Tenoever, B. R., Servant, M. J., and Lin, R. (2003). Convergence of the NF-kappaB and interferon signaling pathways in the regulation of antiviral defense and apoptosis. Ann. N. Y. Acad. Sci. 1010, 237-248. doi: 10.1196/annals.1299.042

Hiscott, J., Pitha, P., Genin, P., Nguyen, H., Heylbroeck, C., Mamane, Y., et al. (1999). Triggering the interferon response: the role of IRF-3 transcription factor. J. Interferon. Cytokine Res. 19, 1-13. doi: 10.1089/107999099314360

Holmes, R. S., Vandeberg, J. L., and Cox, L. A. (2011). Genomics and proteomics of vertebrate cholesterol ester lipase (LIPA) and cholesterol 25-hydroxylase (CH25H). 3 Biotech 1, 99-109. doi: 10.1007/s13205-011-0013-9

Hu, Y., Li, W., Gao, T., Cui, Y., Jin, Y., Li, P., et al. (2017). The severe acute respiratory syndrome coronavirus nucleocapsid inhibits type i interferon production by interfering with TRIM25-mediated RIG-I Ubiquitination. J. Virol. 91, e2143-e2116. 
Huang, C., Zhang, Q., Guo, X. K., Yu, Z. B., Xu, A. T., Tang, J., et al. (2014). Porcine reproductive and respiratory syndrome virus nonstructural protein 4 antagonizes beta interferon expression by targeting the NF-kappaB essential modulator. J. Virol. 88, 10934-10945. doi: 10.1128/jvi.01396-14

Husser, L., Alves, M. P., Ruggli, N., and Summerfield, A. (2011). Identification of the role of RIG-I, MDA-5 and TLR3 in sensing RNA viruses in porcine epithelial cells using lentivirus-driven RNA interference. Virus Res. 159, 9-16. doi: 10.1016/j.virusres.2011.04.005

Imada, K., and Leonard, W. J. (2000). The Jak-STAT pathway. Mol. Immunol. 37, $1-11$.

Jacobs, M. D., and Harrison, S. C. (1998). Structure of an IkappaBalpha/NF-kappaB complex. Cell 95, 749-758.

Kabelitz, D., and Medzhitov, R. (2007). Innate immunity-cross-talk with adaptive immunity through pattern recognition receptors and cytokines. Curr. Opin. Immunol. 19, 1-3. doi: 10.1016/j.coi.2006.11.018

Kawai, T., Takahashi, K., Sato, S., Coban, C., Kumar, H., Kato, H., et al. (2005). IPS1 , an adaptor triggering RIG-I- and Mda5-mediated type I interferon induction. Nat. Immunol. 6, 981-988. doi: 10.1038/ni1243

Ke, H., and Yoo, D. (2017). The viral innate immune antagonism and an alternative vaccine design for PRRS virus. Vet. Microbiol. 209, 75-89. doi: 10.1016/j.vetmic. 2017.03.014

Ke, W., Fang, L., Jing, H., Tao, R., Wang, T., Li, Y., et al. (2017). Cholesterol 25-hydroxylase inhibits porcine reproductive and respiratory syndrome virus replication through enzyme activity-dependent and -independent mechanisms. J. Virol. 91, e00767-19.

Ke, W., Fang, L., Tao, R., Li, Y., Jing, H., Wang, D., et al. (2019). Porcine reproductive and respiratory syndrome virus e protein degrades porcine cholesterol 25-hydroxylase via the ubiquitin-proteasome pathway. J. Virol. 93, e00767-19.

Kensche, T., Tokunaga, F., Ikeda, F., Goto, E., Iwai, K., and Dikic, I. (2012). Analysis of nuclear factor-kappaB (NF-kappaB) essential modulator (NEMO) binding to linear and lysine-linked ubiquitin chains and its role in the activation of NF-kappaB. J. Biol. Chem. 287, 23626-23634. doi: 10.1074/jbc.m112. 347195

Kim, O., Sun, Y., Lai, F. W., Song, C., and Yoo, D. (2010). Modulation of type I interferon induction by porcine reproductive and respiratory syndrome virus and degradation of CREB-binding protein by non-structural protein 1 in MARC-145 and HeLa cells. Virology 402, 315-326. doi: 10.1016/j.virol.2010. 03.039

Kroese, M. V., Zevenhoven-Dobbe, J. C., Bos-De Ruijter, J. N., Peeters, B. P., Meulenberg, J. J., Cornelissen, L. A., et al. (2008). The nsplalpha and nspl papain-like autoproteinases are essential for porcine reproductive and respiratory syndrome virus RNA synthesis. J. Gen. Virol. 89, 494-499. doi: 10.1099/vir.0.83253-0

Kupzig, S., Korolchuk, V., Rollason, R., Sugden, A., Wilde, A., and Banting, G. (2003). Bst-2/HM1.24 is a raft-associated apical membrane protein with an unusual topology. Traffic 4, 694-709. doi: 10.1034/j.1600-0854.2003.00129.x

Labarque, G. G., Nauwynck, H. J., Van Reeth, K., and Pensaert, M. B. (2000). Effect of cellular changes and onset of humoral immunity on the replication of porcine reproductive and respiratory syndrome virus in the lungs of pigs. J. Gen. Virol. 81, 1327-1334. doi: 10.1099/0022-1317-81-5-1327

Labonte, P., Begley, S., Guevin, C., Asselin, M. C., Nassoury, N., Mayer, G., et al. (2009). PCSK9 impedes hepatitis $C$ virus infection in vitro and modulates liver CD81 expression. Hepatology 50, 17-24. doi: 10.1002/hep.22911

Lee, C., Kim, H., Kang, B., Yeom, M., Han, S., Moon, H., et al. (2010). Prevalence and phylogenetic analysis of the isolated type I porcine reproductive and respiratory syndrome virus from 2007 to 2008 in Korea. Virus Genes 40, 225-230. doi: 10.1007/s11262-009-0433-3

Li, H., Zheng, Z., Zhou, P., Zhang, B., Shi, Z., Hu, Q., et al. (2010). The cysteine protease domain of porcine reproductive and respiratory syndrome virus nonstructural protein 2 antagonizes interferon regulatory factor 3 activation. J. Gen. Virol. 91, 2947-2958. doi: 10.1099/vir.0.025205-0

Li, K., Jia, R., Li, M., Zheng, Y. M., Miao, C., Yao, Y., et al. (2015). A sorting signal suppresses IFITM1 restriction of viral entry. J. Biol. Chem. 290, 4248-4259. doi: $10.1074 /$ jbc.m114.630780

Li, Q., and Verma, I. M. (2002). NF-kappaB regulation in the immune system. Nat. Rev. Immunol. 2, 725-734.
Li, S., Li, L., Zhu, H., Shi, M., Fan, H., Gao, Y., et al. (2020). Cholesterol 25hydroxylase inhibits encephalomyocarditis virus replication through enzyme activity-dependent and independent mechanisms. Vet. Microbiol. 245:108658. doi: 10.1016/j.vetmic.2020.108658

Li, Y., Zhou, L., Zhang, J., Ge, X., Zhou, R., Zheng, H., et al. (2014). Nsp9 and Nsp10 contribute to the fatal virulence of highly pathogenic porcine reproductive and respiratory syndrome virus emerging in China. PLoS Pathog. 10:e1004216. doi: 10.1371/journal.ppat.1004216

Liao, Y., Goraya, M. U., Yuan, X., Zhang, B., Chiu, S. H., and Chen, J. L. (2019). Functional involvement of interferon-inducible transmembrane proteins in antiviral immunity. Front. Microbiol. 10:1097.

Liu, C. H., Chaung, H. C., Chang, H. L., Peng, Y. T., and Chung, W. B. (2009). Expression of Toll-like receptor mRNA and cytokines in pigs infected with porcine reproductive and respiratory syndrome virus. Vet. Microbiol. 136, 266-276. doi: 10.1016/j.vetmic.2008.11.016

Liu, G., and Gack, M. U. (2020). Distinct and orchestrated functions of RNA sensors in innate immunity. Immunity 53, 26-42. doi: 10.1016/j.immuni.2020. 03.017

Liu, K., Ma, G., Liu, X., Lu, Y., Xi, S., Ou, A., et al. (2019). Porcine reproductive and respiratory syndrome virus counteracts type I interferon-induced early antiviral state by interfering IRF7 activity. Vet. Microbiol. 229, 28-38. doi: 10.1016/j.vetmic.2018.12.015

Liu, S. Y., Aliyari, R., Chikere, K., Li, G., Marsden, M. D., Smith, J. K., et al. (2013). Interferon-inducible cholesterol-25-hydroxylase broadly inhibits viral entry by production of 25-hydroxycholesterol. Immunity 38, 92-105. doi: 10.1016/j. immuni.2012.11.005

Lopez, O. J., and Osorio, F. A. (2004). Role of neutralizing antibodies in PRRSV protective immunity. Vet. Immunol. Immunopathol. 102, 155-163. doi: 10. 1016/j.vetimm.2004.09.005

Loving, C. L., Brockmeier, S. L., and Sacco, R. E. (2007). Differential type I interferon activation and susceptibility of dendritic cell populations to porcine arterivirus. Immunology 120, 217-229. doi: 10.1111/j.1365-2567.2006. 02493.x

Luo, R., Xiao, S., Jiang, Y., Jin, H., Wang, D., Liu, M., et al. (2008). Porcine reproductive and respiratory syndrome virus (PRRSV) suppresses interferonbeta production by interfering with the RIG-I signaling pathway. Mol. Immunol. 45, 2839-2846. doi: 10.1016/j.molimm.2008.01.028

Luo, X., Chen, X. X., Qiao, S., Li, R., Xie, S., Zhou, X., et al. (2020a). Porcine reproductive and respiratory syndrome virus enhances self-replication via AP1-dependent induction of SOCS1. J. Immunol. 204, 394-407. doi: 10.4049/ jimmunol.1900731

Luo, X., Wang, X., Gao, Y., Zhu, J., Liu, S., Gao, G., et al. (2020b). Molecular mechanism of RNA recognition by zinc-finger antiviral protein. Cell Rep. 30, 46-52.e44.

Lv, L., Zhao, G., Wang, H., and He, H. (2019). Cholesterol 25-Hydroxylase inhibits bovine parainfluenza virus type 3 replication through enzyme activitydependent and -independent ways. Vet. Microbiol. 239:108456. doi: 10.1016/j. vetmic.2019.108456

Malim, M. H., and Emerman, M. (2008). HIV-1 accessory proteins-ensuring viral survival in a hostile environment. Cell Host Microbe. 3, 388-398. doi: 10.1016/ j.chom.2008.04.008

Manokaran, G., Finol, E., Wang, C., Gunaratne, J., Bahl, J., Ong, E. Z., et al. (2015). Dengue subgenomic RNA binds TRIM25 to inhibit interferon expression for epidemiological fitness. Science 350, 217-221. doi: 10.1126/science.aab3369

Madsen, K. G., Hansen, C. M., Madsen, E. S., Strandbygaard, B., Botner, A., and Sorensen, K. J. (1998). Sequence analysis of porcine reproductive and respiratory syndrome virus of the American type collected from Danish swine herds. Arch. Virol. 143, 1683-1700. doi: 10.1007/s007050050409

Martin-Vicente, M., Medrano, L. M., Resino, S., Garcia-Sastre, A., and Martinez, I. (2017). TRIM25 in the regulation of the antiviral innate immunity. Front. Immunol. 8:1187.

Maxwell, K. N., Fisher, E. A., and Breslow, J. L. (2005). Overexpression of PCSK9 accelerates the degradation of the LDLR in a post-endoplasmic reticulum compartment. Proc. Natl. Acad. Sci. U.S.A. 102, 2069-2074. doi: 10.1073/pnas. 0409736102

Meulenberg, J. J. (2000). PRRSV, the virus. Vet. Res. 31, 11-21. doi: 10.1016/j. vetmic. 2004.05 .006 
Miller, L. C., Lager, K. M., and Kehrli, M. E. Jr. (2009). Role of Toll-like receptors in activation of porcine alveolar macrophages by porcine reproductive and respiratory syndrome virus. Clin. Vaccine Immunol. 16, 360-365. doi: 10.1128/ cvi.00269-08

Molitor, T. W., Bautista, E. M., and Choi, C. S. (1997). Immunity to PRRSV: double-edged sword. Vet. Microbiol. 55, 265-276. doi: 10.1016/s0378-1135(96) 01327-2

Murray, P. J. (2007). The JAK-STAT signaling pathway: input and output integration. J. Immunol. 178, 2623-2629. doi: 10.4049/jimmunol.178.5.2623

Music, N., and Gagnon, C. A. (2010). The role of porcine reproductive and respiratory syndrome (PRRS) virus structural and non-structural proteins in virus pathogenesis. Anim. Health Res. Rev. 11, 135-163. doi: 10.1017/ s1466252310000034

Nan, Y., Wu, C., Gu, G., Sun, W., Zhang, Y. J., and Zhou, E. M. (2017). Improved vaccine against PRRSV: current progress and future perspective. Front. Microbiol. 8:1635.

Neil, S., and Bieniasz, P. (2009). Human immunodeficiency virus, restriction factors, and interferon. J. Interferon. Cytokine. Res. 29, 569-580. doi: 10.1089/ jir.2009.0077

Patel, D., Nan, Y., Shen, M., Ritthipichai, K., Zhu, X., and Zhang, Y. J. (2010). Porcine reproductive and respiratory syndrome virus inhibits type I interferon signaling by blocking STAT1/STAT2 nuclear translocation. J. Virol. 84, 1104511055. doi: 10.1128/jvi.00655-10

Posthuma, C. C., Pedersen, K. W., Lu, Z., Joosten, R. G., Roos, N., ZevenhovenDobbe, J. C., et al. (2008). Formation of the arterivirus replication/transcription complex: a key role for nonstructural protein 3 in the remodeling of intracellular membranes. J. Virol. 82, 4480-4491. doi: 10.1128/jvi.027 56-07

Rawlings, J. S., Rosler, K. M., and Harrison, D. A. (2004). The JAK/STAT signaling pathway. J. Cell Sci. 117, 1281-1283.

Rehwinkel, J., and Gack, M. U. (2020). RIG-I-like receptors: their regulation and roles in RNA sensing. Nat Rev Immunol 20, 537-551. doi: 10.1038/s41577-0200288-3

Ruedas-Torres, I., Rodriguez-Gomez, I. M., Sanchez-Carvajal, J. M., Pallares, F. J., Barranco, I., Carrasco, L., et al. (2020). Activation of the extrinsic apoptotic pathway in the thymus of piglets infected with PRRSV-1 strains of different virulence. Vet. Microbiol. 243:108639. doi: 10.1016/j.vetmic.2020. 108639

Sagong, M., and Lee, C. (2011). Porcine reproductive and respiratory syndrome virus nucleocapsid protein modulates interferon-beta production by inhibiting IRF3 activation in immortalized porcine alveolar macrophages. Arch. Virol. 156, 2187-2195. doi: 10.1007/s00705-011-1116-7

Sang, Y., Ross, C. R., Rowland, R. R., and Blecha, F. (2008a). Toll-like receptor 3 activation decreases porcine arterivirus infection. Viral. Immunol. 21, 303-313. doi: 10.1089/vim.2008.0042

Sang, Y., Yang, J., Ross, C. R., Rowland, R. R., and Blecha, F. (2008b). Molecular identification and functional expression of porcine Toll-like receptor (TLR) 3 and TLR7. Vet. Immunol. Immunopathol. 125, 162-167. doi: 10.1016/j.vetimm. 2008.04.017

Schoggins, J. W., Macduff, D. A., Imanaka, N., Gainey, M. D., Shrestha, B., Eitson, J. L., et al. (2014). Pan-viral specificity of IFN-induced genes reveals new roles for cGAS in innate immunity. Nature 505, 691-695. doi: 10.1038/nature 12862

Schoggins, J. W., Wilson, S. J., Panis, M., Murphy, M. Y., Jones, C. T., Bieniasz, P., et al. (2011). A diverse range of gene products are effectors of the type I interferon antiviral response. Nature 472, 481-485. doi: 10.1038/nature 09907

Seidah, N. G., and Chretien, M. (1999). Proprotein and prohormone convertases: a family of subtilases generating diverse bioactive polypeptides. Brain Res. 848 , 45-62. doi: 10.1016/s0006-8993(99)01909-5

Seth, R. B., Sun, L., Ea, C. K., and Chen, Z. J. (2005). Identification and characterization of MAVS, a mitochondrial antiviral signaling protein that activates NF-kappaB and IRF 3. Cell 122, 669-682. doi: 10.1016/j.cell.2005.08. 012

Sheth, U., and Parker, R. (2003). Decapping and decay of messenger RNA occur in cytoplasmic processing bodies. Science 300, 805-808. doi: 10.1126/science. 1082320
Shi, M., Lam, T. T., Hon, C. C., Hui, R. K., Faaberg, K. S., Wennblom, T., et al. (2010a). Molecular epidemiology of PRRSV: a phylogenetic perspective. Virus Res. 154, 7-17. doi: 10.1016/j.virusres.2010.08.014

Shi, M., Lam, T. T., Hon, C. C., Murtaugh, M. P., Davies, P. R., Hui, R. K., et al. (2010b). Phylogeny-based evolutionary, demographical, and geographical dissection of North American type 2 porcine reproductive and respiratory syndrome viruses. J. Virol. 84, 8700-8711. doi: 10.1128/JVI.02551-09

Shi, X., Wang, L., Li, X., Zhang, G., Guo, J., Zhao, D., et al. (2011). Endoribonuclease activities of porcine reproductive and respiratory syndrome virus nsp11 was essential for nsp11 to inhibit IFN-beta induction. Mol. Immunol. 48, 1568-1572. doi: 10.1016/j.molimm.2011.03.004

Snijder, E. J., Van Tol, H., Roos, N., and Pedersen, K. W. (2001). Non-structural proteins 2 and 3 interact to modify host cell membranes during the formation of the arterivirus replication complex. J. Gen. Virol. 82, 985-994. doi: 10.1099/ 0022-1317-82-5-985

Song, C., Krell, P., and Yoo, D. (2010). Nonstructural protein lalpha subunitbased inhibition of NF-kappaB activation and suppression of interferon-beta production by porcine reproductive and respiratory syndrome virus. Virology 407, 268-280. doi: 10.1016/j.virol.2010.08.025

Starr, R., and Hilton, D. J. (1999). Negative regulation of the JAK/STAT pathway. Bioessays 21, 47-52. doi: 10.1002/(sici)1521-1878(199901)21:1<47::aid-bies6> 3.0.co;2-n

Su, Y., Shi, P., Zhang, L., Lu, D., Zhao, C., Li, R., et al. (2018). The superimposed deubiquitination effect of OTULIN and porcine reproductive and respiratory syndrome virus (PRRSV) Nsp11 promotes multiplication of PRRSV. J. Virol. 92, e00175-18.

Sun, Y., Han, M., Kim, C., Calvert, J. G., and Yoo, D. (2012). Interplay between interferon-mediated innate immunity and porcine reproductive and respiratory syndrome virus. Viruses 4, 424-446. doi: 10.3390/v4040424

Sun, Y., Ke, H., Han, M., Chen, N., Fang, W., and Yoo, D. (2016). Nonstructural protein 11 of porcine reproductive and respiratory syndrome virus suppresses both MAVS and RIG-I expression as one of the mechanisms to antagonize type I interferon production. PLoS One 11:e0168314. doi: 10.1371/journal.pone. 0168314

Sun, Z., Chen, Z., Lawson, S. R., and Fang, Y. (2010). The cysteine protease domain of porcine reproductive and respiratory syndrome virus nonstructural protein 2 possesses deubiquitinating and interferon antagonism functions. J. Virol. 84, 7832-7846. doi: 10.1128/jvi.00217-10

Tang, Y. D., Fang, Q. Q., Liu, J. T., Wang, T. Y., Wang, Y., Tao, Y., et al. (2016). Open reading frames $1 \mathrm{a}$ and $1 \mathrm{~b}$ of the porcine reproductive and respiratory syndrome virus (PRRSV) collaboratively initiate viral minus-strand RNA synthesis. Biochem. Biophys. Res. Commun. 477, 927-931. doi: 10.1016/j. bbrc.2016.06.161

Tao, R., Fang, L., Bai, D., Ke, W., Zhou, Y., Wang, D., et al. (2018). Porcine reproductive and respiratory syndrome virus nonstructural protein 4 cleaves porcine DCP1a to attenuate its antiviral activity. J. Immunol. 201, 2345-2353. doi: 10.4049/jimmunol.1701773

Thanawongnuwech, R., Amonsin, A., Tatsanakit, A., and Damrongwatanapokin, S. (2004). Genetics and geographical variation of porcine reproductive and respiratory syndrome virus (PRRSV) in Thailand. Vet. Microbiol. 101, 9-21. doi: 10.1016/j.vetmic.2004.03.005

Thanos, D., and Maniatis, T. (1995). Virus induction of human IFN beta gene expression requires the assembly of an enhanceosome. Cell 83, 1091-1100. doi: 10.1016/0092-8674(95)90136-1

Theofilopoulos, A. N., Baccala, R., Beutler, B., and Kono, D. H. (2005). Type I interferons (alpha/beta) in immunity and autoimmunity. Annu. Rev. Immunol. 23, 307-336. doi: 10.1146/annurev.immunol.23.021704.115843

Wang, D., Chen, J., Yu, C., Zhu, X., Xu, S., Fang, L., et al. (2019). Porcine reproductive and respiratory syndrome virus nspl1 antagonizes type i interferon signaling by targeting IRF9. J. Virol. 93, e00623-19.

Wang, D., Fan, J., Fang, L., Luo, R., Ouyang, H., Ouyang, C., et al. (2015). The nonstructural protein 11 of porcine reproductive and respiratory syndrome virus inhibits NF-kappaB signaling by means of its deubiquitinating activity. Mol. Immunol. 68, 357-366. doi: 10.1016/j.molimm.2015. 08.011

Wang, D., Fang, L., Li, T., Luo, R., Xie, L., Jiang, Y., et al. (2008). Molecular cloning and functional characterization of porcine IFN-beta promoter stimulator 1 
(IPS-1). Vet. Immunol. Immunopathol. 125, 344-353. doi: 10.1016/j.vetimm. 2008.05.018

Wang, G., Yu, Y., Cai, X., Zhou, E. M., and Zimmerman, J. J. (2020). Effects of PRRSV infection on the porcine thymus. Trends Microbiol. 28, 212-223. doi: 10.1016/j.tim.2019.10.009

Wang, G., Yu, Y., He, X., Wang, M., Cai, X., and Zimmerman, J. J. (2019). Porcine reproductive and respiratory syndrome virus infection of bone marrow: lesions and pathogenesis. Virus Res. 265, 20-29. doi: 10.1016/j.virusres.2019. 02.019

Wang, G., and Zheng, C. (2020). Zinc finger proteins in the host-virus interplay: multifaceted functions based on their nucleic acid-binding property. FEMS Microbiol. Rev. 45:fuaa059.

Wang, R., Nan, Y., Yu, Y., Yang, Z., and Zhang, Y. J. (2013a). Variable interference with interferon signal transduction by different strains of porcine reproductive and respiratory syndrome virus. Vet. Microbiol. 166, 493-503. doi: 10.1016/j. vetmic.2013.07.022

Wang, R., Nan, Y., Yu, Y., and Zhang, Y. J. (2013b). Porcine reproductive and respiratory syndrome virus Nsplbeta inhibits interferon-activated JAK/STAT signal transduction by inducing karyopherin-alphal degradation. J. Virol. 87, 5219-5228. doi: 10.1128/jvi.02643-12

Wang, T. Y., Fang, Q. Q., Cong, F., Liu, Y. G., Wang, H. M., Zhang, H. L., et al. (2019). The Nsp12-coding region of type 2 PRRSV is required for viral subgenomic mRNA synthesis. Emerg. Microbes. Infect. 8, 1501-1510. doi: 10. 1080/22221751.2019.1679010

Wang, T. Y., Liu, Y. G., Li, L., Wang, G., Wang, H. M., Zhang, H. L., et al. (2018). Porcine alveolar macrophage CD163 abundance is a pivotal switch for porcine reproductive and respiratory syndrome virus infection. Oncotarget 9, 12174-12185. doi: 10.18632/oncotarget. 24040

Wang, X., Li, C., Zhou, L., Zhang, N., Ge, X., Guo, X., et al. (2014). Porcine reproductive and respiratory syndrome virus counteracts the porcine intrinsic virus restriction factors-IFITM1 and Tetherin in MARC-145 cells. Virus Res. 191, 92-100. doi: 10.1016/j.virusres.2014.07.025

Wei, Z. Y., Liu, F., Li, Y., Wang, H. L., Zhang, Z. D., Chen, Z. Z., et al. (2020). Aspartic acid at residue 185 modulates the capacity of HP-PRRSV nsp4 to antagonize IFN-I expression. Virology 546, 79-87. doi: 10.1016/j.virol.2020. 04.007

Wensvoort, G., Terpstra, C., Pol, J. M., Ter Laak, E. A., Bloemraad, M., De Kluyver, E. P., et al. (1991). Mystery swine disease in The Netherlands: the isolation of Lelystad virus. Vet. Q. 13, 121-130. doi: 10.1080/01652176.1991.9694296

Wu, B., and Hur, S. (2015). How RIG-I like receptors activate MAVS. Curr. Opin. Virol. 12, 91-98. doi: 10.1016/j.coviro.2015.04.004

Wu, C., Shi, B., Yang, D., Zhang, K., Li, J., Wang, J., et al. (2020). Porcine reproductive and respiratory syndrome virus promotes SLA-DR-mediated antigen presentation of nonstructural proteins to evoke a nonneutralizing antibody response in vivo. J. Virol. 94, e01423-20.

Wysocki, M., Chen, H., Steibel, J. P., Kuhar, D., Petry, D., Bates, J., et al. (2012). Identifying putative candidate genes and pathways involved in immune responses to porcine reproductive and respiratory syndrome virus (PRRSV) infection. Anim. Genet. 43, 328-332. doi: 10.1111/j.1365-2052.2011. 02251.x

Xiao, Z., Batista, L., Dee, S., Halbur, P., and Murtaugh, M. P. (2004). The level of virus-specific $\mathrm{T}$-cell and macrophage recruitment in porcine reproductive and respiratory syndrome virus infection in pigs is independent of virus load. J. Virol. 78, 5923-5933. doi: 10.1128/jvi.78.11.5923-5933.2004

Yang, L., He, J., Wang, R., Zhang, X., Lin, S., Ma, Z., et al. (2019). Nonstructural protein 11 of porcine reproductive and respiratory syndrome virus induces STAT2 degradation to inhibit interferon signaling. J. Virol. 93, e1352e1319.
Yang, L., and Zhang, Y. J. (2017). Antagonizing cytokine-mediated JAK-STAT signaling by porcine reproductive and respiratory syndrome virus. Vet. Microbiol. 209, 57-65. doi: 10.1016/j.vetmic.2016.12.036

Yoneyama, M., Suhara, W., and Fujita, T. (2002). Control of IRF-3 activation by phosphorylation. J. Interferon Cytokine Res. 22, 73-76. doi: 10.1089/ 107999002753452674

Yoneyama, M., Suhara, W., Fukuhara, Y., Fukuda, M., Nishida, E., and Fujita, T. (1998). Direct triggering of the type I interferon system by virus infection: activation of a transcription factor complex containing IRF-3 and CBP/p300. EMBO J. 17, 1087-1095. doi: 10.1093/emboj/17.4.1087

Yoo, D., Song, C., Sun, Y., Du, Y., Kim, O., and Liu, H. C. (2010). Modulation of host cell responses and evasion strategies for porcine reproductive and respiratory syndrome virus. Virus Res. 154, 48-60. doi: 10.1016/j.virusres.2010. 07.019

Zhang, L., and Pagano, J. S. (2002). Structure and function of IRF-7. J. Interferon Cytokine Res. 22, 95-101. doi: 10.1089/107999002753452700

Zhang, Q., Huang, C., Yang, Q., Gao, L., Liu, H. C., Tang, J., et al. (2016). MicroRNA-30c Modulates Type I IFN Responses To Facilitate Porcine Reproductive and Respiratory Syndrome Virus Infection by Targeting JAK1. J. Immunol. 196, 2272-2282. doi: 10.4049/jimmunol.1502006

Zhang, Y., Gao, F., Li, L., Zhao, K., Jiang, S., Jiang, Y., et al. (2020). porcine reproductive and respiratory syndrome virus antagonizes PCSK9's antiviral effect via nsp11 endoribonuclease activity. Viruses 12:655. doi: 10.3390/ v12060655

Zhao, K., Li, L. W., Jiang, Y. F., Gao, F., Zhang, Y. J., Zhao, W. Y., et al. (2019a). Nucleocapsid protein of porcine reproductive and respiratory syndrome virus antagonizes the antiviral activity of TRIM25 by interfering with TRIM25mediated RIG-I ubiquitination. Vet. Microbiol. 233, 140-146. doi: 10.1016/j. vetmic.2019.05.003

Zhao, Y., Song, Z., Bai, J., Liu, X., Nauwynck, H., and Jiang, P. (2019b). ZAP, a CCCH-type zinc finger protein, inhibits porcine reproductive and respiratory syndrome virus replication and interacts with viral Nsp9. J. Virol. 93, e00001-e19.

Zhao, Y., Song, Z., Bai, J., Liu, X., Nauwynck, H., and Jiang, P. (2020). Porcine reproductive and respiratory syndrome virus Nsp4 cleaves ZAP to antagonize its antiviral activity. Vet. Microbiol. 250:108863. doi: 10.1016/j.vetmic.2020. 108863

Zheng, C. (2018). Evasion of Cytosolic DNA-Stimulated Innate Immune Responses by HSV-1. J. Virol. 92, e00099-17.

Zhu, H., and Zheng, C. (2020). the race between host antiviral innate immunity and the immune evasion strategies of herpes simplex virus 1. Microbiol Mol Biol Rev 84, e00099-20.

Zhu, Y., Chen, G., Lv, F., Wang, X., Ji, X., Xu, Y., et al. (2011). Zinc-finger antiviral protein inhibits HIV-1 infection by selectively targeting multiply spliced viral mRNAs for degradation. Proc Natl Acad Sci U.S.A. 108, 15834-15839. doi: 10.1073/pnas.1101676108

Conflict of Interest: The authors declare that the research was conducted in the absence of any commercial or financial relationships that could be construed as a potential conflict of interest.

Copyright (C) 2021 Wang, Sun, Zhang, Wang, Zhan, Tian, Cai, Su and Tang. This is an open-access article distributed under the terms of the Creative Commons Attribution License (CC BY). The use, distribution or reproduction in other forums is permitted, provided the original author(s) and the copyright owner(s) are credited and that the original publication in this journal is cited, in accordance with accepted academic practice. No use, distribution or reproduction is permitted which does not comply with these terms. 